\title{
An Identification Method of a Mechanical Hybrid System Switched by the Absolute Value of Velocity or Displacement
}

\author{
Mitsuo Hirata Member (Utsunomiya University) \\ Sakae Noguchi Non-member (Utsunomiya University) \\ Shuichi Adachi Member (Keio University)
}

Keywords: hybrid systems, system identification, support vector machines, kernel method, mechanical system

The systems containing both continuous dynamics described by differential equations and discrete events such as $\mathrm{ON} / \mathrm{OFF}$ switches are referred to as hybrid system. Recently, the system identification of hybrid systems have received more attention not only in academia but also in industry. In this study, an identification method of a hybrid mechanical system switched by the absolute value of velocity or displacement as shown in Fig.1 is considered.

On the identification of the hybrid systems, parameters and region of each submodel on the regression vector space are estimated. A support vector machine (SVM) is usually applied to separate the regression vector space by a hyperplane. However, we have shown that the regression vector space of the system shown in Fig.1 can not be separated by a linear discriminant function in the following cases:

- The spring constant $k$ or the damping coefficient $c$ is switched by the velocity of the mass $m$.

- The damping coefficient $c$ is switched by the position of the mass $m$.

For these cases, we propose an identification method based on SVM with polynomial kernel, and the effectiveness is shown by simulations.

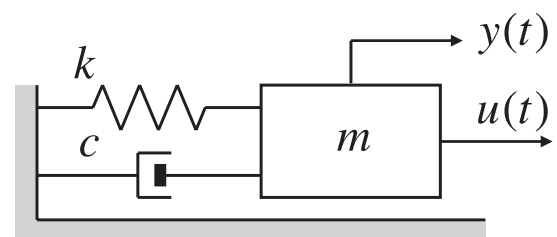

Fig. 1. Spring-mass-damper system
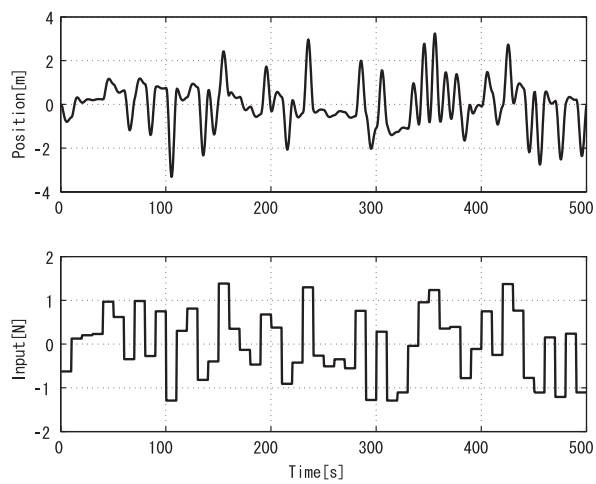

Fig. 2. Input-output data (upper: output, lower: input)
Fig.2 shows input-output data collected by the springmass-damper system shown by Fig.1, where the damping coefficient $c$ is switched by the absolute value of the velocity of the mass $m$. After the data clustering using the K-means method, SVM with polynomial kernel is applied to separate the regression vector space. Fig. 3 shows the regression vector space, and the solid line shows the estimated boundary which separates two modes. Fig. 4 shows the time responses when the validation input is applied to the identified hybrid system. The solid line shows the actual output, and the dashdot line shows the output obtained by the proposed method. The output of the conventional method using a single ARX model is also shown by the dashed line. The fit ratio is $89.4 \%$ for the proposed method and $68.2 \%$ for the conventional method. This result indicates the effectiveness of the proposed method.

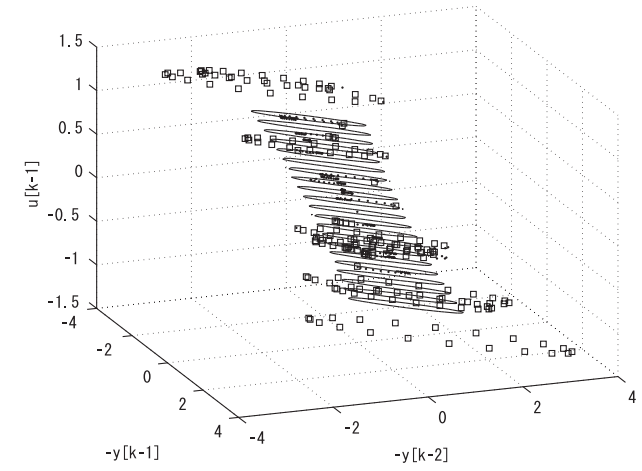

Fig. 3. Regression space (dots: mode 1, squares: mode 2 , solid line: estimated boundary)

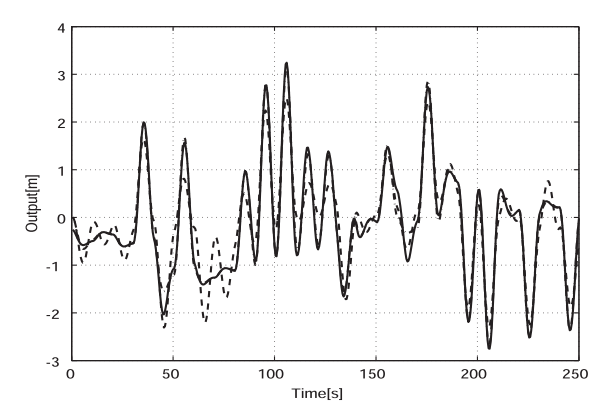

Fig. 4. Time responses of identified models (solid line: true model, dashed line: single ARX model, dashdot line: hybrid model) 


\title{
速度や変位の絶対值で切り替わる メカニカルハイブリッドシステムの同定法
}

\author{
正員 平田 光男* 非会員 野口 栄* \\ 正 員 足立 修一**
}

An Identification Method of a Mechanical Hybrid System

Switched by the Absolute Value of Velocity or Displacement

Mitsuo Hirata*, Member, Sakae Noguchi*, Non-member, Shuichi Adachi**, Member

\begin{abstract}
In this paper, we propose a system identification method for hybrid systems switched by the absolute value of velocity or displacement. First, it is shown that the regression vector space of a mechanical system switched by the absolute value of velocity or displacement cannot be separated by a hyperplane. Then a method based on support vector machines with a polynomial kernel is proposed. The effectiveness is shown by simulations using a spring-mass-damper system.
\end{abstract}

キーワード：ハイブリッドシステム, システム同定, サポートベクターマシン, カーネル法, メカニカルシステム

Keywords: hybrid systems, system identification, support vector machines, kernel method, mechanical system

\section{1. はじめに}

微分方程式などにより記述される連続的な動特性と，ス イッチの ON/OFF などの離散事象が混在したシステムを ハイブリッドシステムという。近年，ハイブリッドシステム に対する制御系設計や同定法などの研究がさかんに行われ ている。同定問題においては，同定対象から取得した入出力 データのみを用いて，ハイブリッドシステムの数学的表現 法の一つである区分的アファイン (PWA: piecewise affine) システムを同定する方法が提案されている(1)。この方法で は，局所モデルを K-means 法などデータクラスタリングに より分類し，それらのパラメータを最小二乗法で推定した あと, 回帰べクトル空間（以下，回帰空間）を線形分離する 超平面をサポートベクターマシン (SVM: support vector machines) (1) (2) を用いて求める, という手順がとられる。 しかしながら，バネ-マス-ダンパで構成される 1 自由度振 動系のようなメカニカルシステムにおいて，バネ定数や粘 性摩擦係数が速度や变位の大きさ，つまり，絶対值によっ て切り替わる場合を想定すると, 各局所モデルに対応する

\footnotetext{
* 宇都宮大学工学部

₹ 321-8585 栃木県宇都宮市陽東 7-1-2

Utsunomiya University

7-1-2, Yoto, Utsunomiya, Tochigi 321-8585

** 慶應義塾大学理工学部

干 223-8522 神奈川県横浜市港北区日吉 3-14-1

Keio University

3-14-1, Hiyoshi, Kohoku-ku, Yokohama, Kanagawa 223-8522
}

回帰ベクトルを線形分離することができなくなることが示 せる。したがって，文献 (1) の方法を直接適用できない。

このように, 速度や変位の絶対值でモデルが切り替わる という問題設定は, 現実のメカニカルシステムにおいて, ご く自然に起こり得る。たとえば，ハードディスクのへッド アクチュエータでは, 磁気ヘッドの変位量や速度の絶対值 によって, 制御対象の特性が異なることが知られている ${ }^{(4)}$ 。 また，リニアボールガイドのナノメートル領域の位置決め においても, 微少動作時と, それ以外において, 制御対象 の挙動が異なることが示されている(5)。しかし，モデルが 切り替わる物理現象やメカニズムの解明は必ずしも容易で はなく, 入出力データからモデルが得られるシステム同定 法は有効な手段となる。

そこで本稿では, 速度や变位が絶対值で切り替わるバネ一 マスーダンパシステムのシステム同定問題を考える。まず, 速度の絶対值によって粘性摩擦係数が切り替わる 1 自由度 振動系を例にとって, その回帰べクトルが回帰空間上でど のように分離されるか, について考察する。続いて, 変位の 絶対值で粘性摩擦係数が切り替わる場合, 速度や变位の絶 対值でバネ定数が切り替わる場合に対する考察を行う。そ して，これらを分離するために，多項式カーネルを用いた SVM による手法を提案する。さらに, 計算機上に構築し たハイブリッドモデルの入出力データを用いてハイブリッ ド同定をおこない，提案手法の有効性を示す。 


\section{2. ハイブリッドシステムの同定}

本節では，文献 (1) で示されたハイブリッドシステムの同 定手順について説明する。まず，同定モデルは次式に示すよ うに $s$ 個のモードからなる区分的 ARX モデル (PWARX: piecewise ARX) とする。

$$
y[k]=\left\{\begin{array}{cc}
\boldsymbol{\theta}_{1}^{T} \boldsymbol{\varphi}[k]+w[k], & \text { if } \boldsymbol{\varphi}[k] \in C_{1} \\
\vdots & \\
\boldsymbol{\theta}_{s}^{T} \boldsymbol{\varphi}[k]+w[k], & \text { if } \boldsymbol{\varphi}[k] \in C_{s}
\end{array}\right.
$$

ここで, $k=0,1,2, \cdots$ は時刻, $w[k]$ は白色雑音， $\boldsymbol{\theta}_{i}$, $i=1, \ldots, s$ はパラメータベクトル, $\boldsymbol{\varphi}[k]$ は回帰ベクト ルであり，それぞれ次式で定義する。

$$
\begin{array}{r}
\boldsymbol{\theta}_{i}:=\left[a_{i 1}, \ldots, a_{i n}, b_{i 1}, \ldots, b_{i n}\right]^{T} \\
\varphi[k]:=[-y[k-1], \ldots,-y[k-n], \\
u[k-1], \ldots, u[k-n]]^{T}
\end{array}
$$

ただし， $n$ はPWARX モデルの次数であり，すべてのモー ドで同じとする。また， $u[k], y[k]$ は，それぞれ入力と出力で ある。また, $\{C\}_{i=1}^{s}$ はポリトープであり, well-posedness 条件 $\cup_{i=1}^{s} C_{i}=C, C_{i} \cap C_{j}=\emptyset, \forall i \neq j$ を満たすものと する。

〈2・1〉 データクラスタリング入出力データ $(u[k]$, $y[k])_{k=1}^{N}$ が与えられたとき, 次の手順に従ってデータクラ スタリングを行う。

Step 1 データセット $(\varphi[k], y[k])_{i=1}^{N}$ を, $N_{c}$ 個のデータ セットから構成されるクラスタ $\mathcal{C}_{j}$ に分ける。具体的に は, $(\boldsymbol{\varphi}[j], y[j])$ 自身と, $(\boldsymbol{\varphi}[j], y[j])$ に近いものから順 番に $N_{c}-1$ 個集めたものをクラスタ $\mathcal{C}_{j}$ とする。ただ し, 距離はユークリッドノルム $\|\varphi[j]-\varphi[i]\|$ で定義 する。

Step 2 すべてのクラスタ $\mathcal{C}_{j}$ に対して, パラメータベク トル $\boldsymbol{\theta}^{L S, j}$ を最小 2 乗法を用いて次式から求める。

$$
\begin{aligned}
& \boldsymbol{\theta}^{L S, j}=\left(\boldsymbol{\Phi}_{j}^{T} \boldsymbol{\Phi}_{j}\right)^{-1} \boldsymbol{\Phi}_{j}^{T} \boldsymbol{y}_{\mathcal{C}_{j}}, \quad j=1, \cdots, N \\
& \boldsymbol{\Phi}_{j}=\left[\boldsymbol{\varphi}_{1}, \cdots, \boldsymbol{\varphi}_{N_{c}}\right]^{T}, \quad \boldsymbol{y}_{\mathcal{C}_{j}}=\left[y_{1}, \cdots, y_{N_{c}}\right]^{T}
\end{aligned}
$$
ただし， $\left(\boldsymbol{\varphi}_{i}, y_{i}\right)_{i=1}^{N_{c}}$ は, クラスタ $\mathcal{C}_{j}$ に属すデータセッ トである。

Step 3 K-means 法によって, Step 2 で求めたパラメー タベクトル $\boldsymbol{\theta}^{L S, j}$ をパラメータ空間上で局所モデルの 数 $s$ 個に分類する。ここで，K-means 法は分類アルゴ リズムの代表的な手法で，クラスタ $\mathcal{D}_{i},(i=1, \ldots, s)$ に属するパラメータベクトル $\boldsymbol{\theta}^{L S, j}$ と， $\mathcal{D}_{i}$ に含まれる パラメータベクトルの平均值 $\boldsymbol{\mu}_{i}$ を更新しながら以下 の評価関数を最小化する手法である。

$$
J=\sum_{i=1}^{s} \sum_{\boldsymbol{\theta}^{L S, j} \in \mathcal{D}_{i}}\left\|\boldsymbol{\theta}^{L S, j}-\boldsymbol{\mu}_{i}\right\|^{2}
$$

Step 4 Step 3 で得られたパラメー夕空間上での分類結 果に基づき，もとのデータセット $(\boldsymbol{\varphi}[k], y[k])_{i=1}^{N}$ を $s$

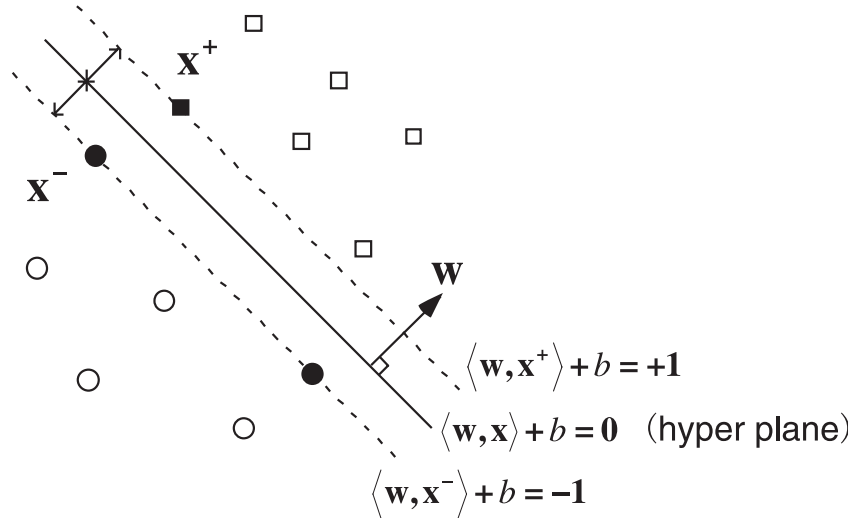

図 1 トレーニングデータと分離超平面

Fig. 1. Training data and hyperplane

個に分類する。パラメータ空間とデータセットには 1 対 1 の対応関係があるのでこの作業は機械的に行うこ とができる。

クラスタリングされた各モードのデータセットそれぞれに 対して, 最小 2 乗推定を適用することで各局所モデルに対 する ARX モデルを同定することができる。

〈2・2〉 SVM による境界面の推定 クラスタリング されたデータを用いて，局所モデルの動作領域の境界面を SVM により推定する。SVM はパターン認識問題に対し て最も優れた学習機械の 1 つとして知られている(2)(3)。入 力データ $\boldsymbol{x}_{i} \in \mathcal{R}^{n}$ と, それに対応する 2 值のクラスラベ ル $y_{i} \in\{-1,1\}$ からなるトレーニングデータ $\left(\boldsymbol{x}_{i}, y_{i}\right), i=$ $1, \cdots, N$ を次式のような線形識別関数で分離する。

$$
f\left(\boldsymbol{x}_{i}\right)=\left\langle\boldsymbol{w}, \boldsymbol{x}_{i}\right\rangle+b
$$

ここで, $\langle\cdot, \cdot\rangle$ は内積, $\boldsymbol{w}$ は分離超平面の法線ベクトルであ り, $b$ はバイアス項である。データが図 1 のように線形分 離できるとき, 汎化能力が最も高い超平面は, マージン $\gamma$ が最大となる超平面である。

このマージン最大化問題は，以下のような線形制約付き 2 次最適化問題 (主問題) として定式化できる。

$$
\min _{\boldsymbol{w}, b} \mathcal{J}(\boldsymbol{w})=\frac{1}{2}\langle\boldsymbol{w}, \boldsymbol{w}\rangle
$$

subject to $\quad\left(\left\langle\boldsymbol{w}, \boldsymbol{x}_{i}\right\rangle+b\right) y_{i} \geq 1$,

$$
i=1, \cdots, N
$$

このとき，マージンは $\gamma=1 /\|\boldsymbol{w}\|$ となる。この最適化問 題のラグランジュ関数は次式のようになる。

$$
\mathcal{L}(\boldsymbol{w}, b, \boldsymbol{\alpha})=\langle\boldsymbol{w}, \boldsymbol{w}\rangle-\sum_{i=1}^{N} \alpha_{i}\left\{\left(\left\langle\boldsymbol{w}, \boldsymbol{x}_{i}\right\rangle+b\right) y_{i}-1\right\}
$$

（4）式を $\boldsymbol{w}, b$ で微分し，0 とおいたものを，(4) 式に代入し て整理すると, 以下のような最適化問題 (双対問題) が得ら れる。 


$$
\begin{aligned}
\max _{\alpha} \mathcal{Q}(\alpha)= & \sum_{i=1}^{N} \alpha_{i}-\frac{1}{2} \sum_{i, j=1}^{N} y_{i} y_{j} \alpha_{i} \alpha_{j}\left\langle\boldsymbol{x}_{i}, \boldsymbol{x}_{j}\right\rangle \\
\text { subject to } & \sum_{i=1}^{N} y_{i} \alpha_{i}=0 \ldots \ldots \ldots \ldots \ldots \ldots \\
& \alpha_{i} \geq 0, i=1, \cdots, N
\end{aligned}
$$

最適解 $\alpha_{i}$ のうち $\alpha_{i}>0$ となるものはサポートベクターと 呼ばれ, 分離超平面の構成に寄与するデータである。

ところで，図 2 のように，データが線形分離不可能な場 合, 入力データ $\boldsymbol{x}_{i}$ を非線形関数 $\phi(\cdot)$ により高次元特徵空 間に写像すると，線形分離可能になる場合がある。これは， (2) 式の代わりに次の非線形識別関数を用いることを意味 する。

$$
f\left(\boldsymbol{x}_{i}\right)=\left\langle\boldsymbol{w}, \boldsymbol{\phi}\left(\boldsymbol{x}_{i}\right)\right\rangle+b
$$

一般に, $\boldsymbol{x}_{i}$ の次元が妥当なものであっても, $\boldsymbol{\phi}\left(\boldsymbol{x}_{i}\right)$ の次元 が著しく増大し，計算が不可能になることが多い。ところ が，(5) 式の双対問題では

$$
\max _{\alpha} \mathcal{Q}(\alpha)=\sum_{i=1}^{N} \alpha_{i}-\frac{1}{2} \sum_{i, j=1}^{N} y_{i} y_{j} \alpha_{i} \alpha_{j}\left\langle\phi\left(\boldsymbol{x}_{i}\right), \boldsymbol{\phi}\left(\boldsymbol{x}_{j}\right)\right\rangle
$$

のように，特徵空間は陽に表れず，内積だけ直接計算でき れば良いことがわかる。この内積をカーネル関数と呼び次 式で定義する(2)。

$$
K\left(\boldsymbol{x}_{i}, \boldsymbol{x}_{j}\right)=\left\langle\boldsymbol{\phi}\left(\boldsymbol{x}_{i}\right), \boldsymbol{\phi}\left(\boldsymbol{x}_{j}\right)\right\rangle
$$

カーネル関数を用いることで，特徵空間の次元増大による 計算量の問題，すなわち次元の呪いを回避でき，これはカー ネルトリックとしてよく知られている。

SVM でよく用いられるカーネルとして，多項式カーネ ル，ガウスカーネル，シグモイドカーネルがある。たとえ ば，多項式カーネルは

$$
K\left(\boldsymbol{x}_{i}, \boldsymbol{x}_{j}\right)=\left\langle\boldsymbol{x}_{i}, \boldsymbol{x}_{j}\right\rangle^{d} \ldots
$$

または

$$
K\left(\boldsymbol{x}_{i}, \boldsymbol{x}_{j}\right)=\left(\left\langle\boldsymbol{x}_{i}, \boldsymbol{x}_{j}\right\rangle+1\right)^{d}
$$

と定義される。

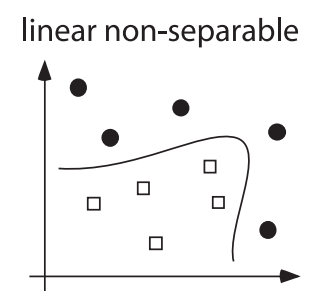

input space $\mathbf{X}$

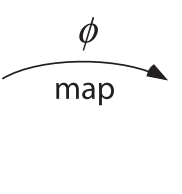

2 高次元特徵空間への写像

Fig. 2. Mapping to higher dimensional feature space

\section{3. 速度や変位の絶対值によって切り替わるハイブ リッドシステムの同定}

\section{$\langle 3 \cdot 1\rangle$ 速度の絶対值でシステムが切り替わる場合}

図 3 に示す 1 自由度振動系を考える。図 3 において, $m$ は質量 $[\mathrm{kg}], k$ はバ六定数 $[\mathrm{N} / \mathrm{m}], c$ は粘性摩擦係数 $[\mathrm{Ns} / \mathrm{m}]$ である。出力 $y(t)$ を $m$ の平衡点からの变位 $[\mathrm{m}]$, 入力 $u(t)$ を $m$ に加える力 $[\mathrm{N}]$ とする。すると, 運動方程式は, 次式 となる。

$$
m \ddot{y}(t)+c \dot{y}(t)+k y(t)=u(t) \cdot
$$

ここで, 速度の絶対值によって粘性摩擦係数が切り替わ るシステムを考えよう。まず，(9) 式を 2 種類の粘性摩擦 係数 $c=c_{1}, c_{2}$ に対してサンプリング周期 $T_{s}$ でゼロ次ホー ルドを用いて離散化したモデルを

$$
y[k]=\boldsymbol{\theta}_{i}^{T} \boldsymbol{\varphi}[k], \quad i=1,2 .
$$

と定義する。ただし， $\boldsymbol{\theta}_{1}, \boldsymbol{\theta}_{2}$ はそれぞれ $c=c_{1}, c_{2}$ に対す るパラメータベクトル, $\varphi[k]$ は次式で定義される回帰ベク トルである。

$$
\boldsymbol{\varphi}[k]:=[-y[k-1],-y[k-2], u[k-1], u[k-2]]^{T}
$$

また, $y[k]=y\left(T_{s} k\right), u[k]=u\left(T_{s} k\right)$ である。そして, $y[k]$ の速度を後退差分を用いて

$$
v[k-1]:=\frac{y[k-1]-y[k-2]}{T_{s}}
$$

と定義し，この絶対值によって切り替わる次のハイブリッ ドシステムを考える。

$$
y[k]= \begin{cases}\boldsymbol{\theta}_{1}^{T} \boldsymbol{\varphi}[k] & \text { if }|v[k-1]|<V_{s w} \\ \boldsymbol{\theta}_{2}^{T} \boldsymbol{\varphi}[k] & \text { if }|v[k-1]| \geq V_{s w}\end{cases}
$$

ここで, $|v[k-1]|<V_{s w}$ を満たすとき mode $1,|v[k-1]| \geq$ $V_{s w}$ を満たすとき mode 2 とよび, 以後, このハイブリッ ドシステムに対する同定問題を考えていく。

簡単のため $u[k]=0, \forall k$ の場合を考え, $y[k-2]-y[k-1]$ 平面上，つまり回帰空間上において，y[k]の軌跡と各モー ドとの対応関係を求めよう。すると，(12) 式から図 4 が得 られる。これから, mode 1 のとき, $y[k]$ の軌跡は領域 $C_{b}$ 上にあり, mode 2 のときは領域 $C_{a}$ または $C_{c}$ 上にあるこ とがわかる。したがって, mode 1 と mode 2 を, 回帰空

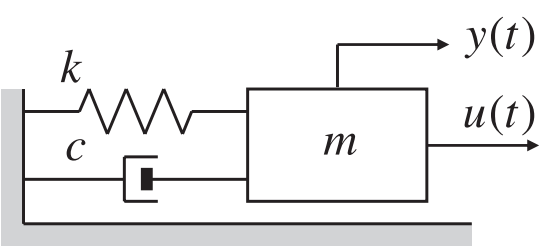

図 3 バネ-マス-ダンパシステム

Fig. 3. Spring-mass-damper system 


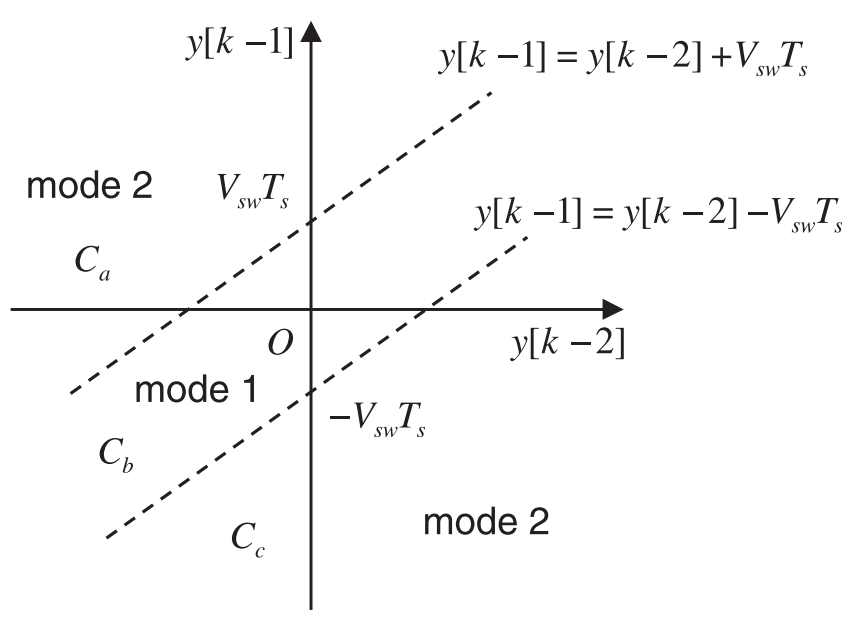

困 4 回帰空間

Fig. 4. Regression vector space

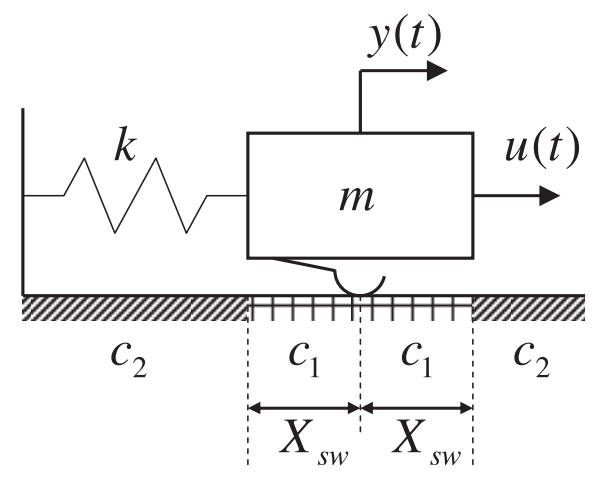

図 5 変位によってダンパが切り替わるシステム

Fig. 5. A damper switched system by displacement

間上で 1 本の直線を用いて分割することはできない。そこ で, 領域 $C_{a}$ と $C_{b}$ 及び $C_{b}$ と $C_{c}$ はそれぞれ直線で分割で きることに注意し, mode 2 をさらに 2 つに分割し, 領域 $C_{a}$ を mode $2 \mathrm{a}$, 領域 $C_{c}$ を mode $2 \mathrm{~b}$ としょう。つまり, (13) 式のシステムを 3 つのモードからなるシステムと仮定 する。ところが, mode $2 \mathrm{a}$, mode $2 \mathrm{~b}$ どちらの場合も，パ ラメータベクトルは $\theta_{2}$ となるため, パラメータ空間と回帰 空間が 1 対 1 に対応しない。前章で述べた文献 (1)のハイ ブリッド同定法は, Step 4 でデータセットを回帰空間上で 分割する際に，パラメータ空間とデータセットが 1 対 1 に 対応している必要がある。よって，このままでは，(13) 式 に対し，文献 (1) の手法を適用することができない。図 3 において，速度の絶対值によって $k$ が $k_{1}, k_{2}$ に切り替わる システムを考えた場合も，同様にしてここで述べた問題が 生じることが示せる。

$\langle 3 \cdot 2\rangle$ 変位の絶対值でシステムが切り替わる場合 変 位によって粘性摩擦係数が切り替わる場合として, 図 5 の システムを考えよう。このシステムは, 質量 $m$ の物体と床 との間に粘性摩擦が存在し, $|y(t)|<X_{s w}($ mode 1) では, 粘性摩擦係数が $c_{1}$ となり，それ以外 (mode 2) では， $c_{2}$ と なる。(9) 式の運動方程式は, $y(t) \leq-X_{s w}$ と $y(t) \geq X_{s w}$

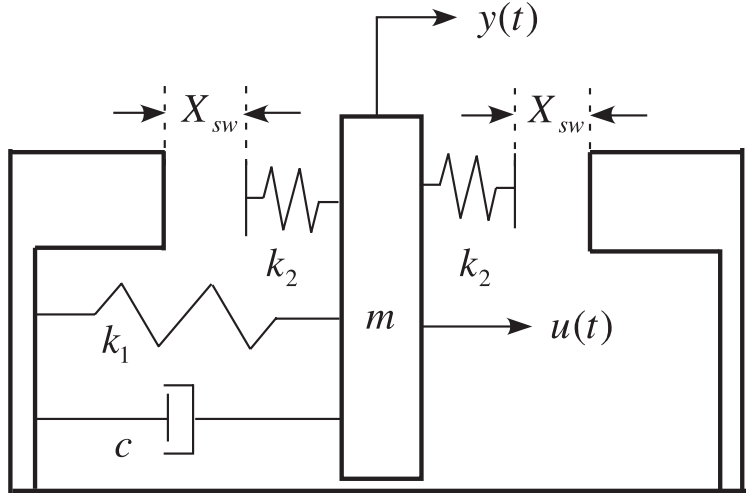

図 6 変位によってバネが切り替わるシステム

Fig. 6. A spring switched system by displacement

で同じになることから，両者を区別することができない。 よって,〈3・1〉節と同じ問題が生じる。

一方，物体の変位によってバネが切り替わる場合として 図 6 のシステムを考えよう。図 6 では, $|y(t)| \geq X_{s w}$ のと き，バネ $k_{1}$ とバネ $k_{2}$ が並列結合されるようになっており， そのシステムの運動方程式は

(i) $-X_{s w}<y(t)<X_{s w}$ (mode 1) のとき $m \ddot{y}(t)+c \dot{y}(t)+k_{1} y(t)=u(t)$

(ii) $y(t) \geq X_{s w}$ (mode 2a)のとき $m \ddot{y}(t)+c \dot{y}(t)+\left(k_{1}+k_{2}\right) y(t)+k_{2} X_{s w}=u(t)$

(iii) $y(t) \leq-X_{s w}$ (mode $\left.2 \mathrm{~b}\right)$ のとき

$$
m \ddot{y}(t)+c \dot{y}(t)+\left(k_{1}+k_{2}\right) y(t)-k_{2} X_{s w}=u(t)
$$

となる。(15) 式と (16) 式で定数項 $k_{2} X_{s w}$ の符号が異なるた め mode $2 \mathrm{a}$ と mode $2 \mathrm{~b}$ のパラメータベクトル $\boldsymbol{\theta}_{i}, i=1,2$ が区別でき，すべてのモードにおいて，パラメータ空間と 回帰空間が 1 対 1 に対応する。したがって, $C_{a}$ と $C_{b}, C_{b}$ と $C_{c}$ をそれぞれ直線で分割することができるので，文献 (1)の手法が適用できる。

\section{〈3·3〉多項式カーネルを用いたハイブリッド同定法}

前節の考察から, 図 6 の場合を除いて, 速度や变位の絶 対值でモデルが切り替わると, 回帰空間を mode 1 と mode 2 に線形分離できないことがわかった。そこで, mode 1 と mode 2 を非線形分離することを考えよう。図 4 より領域 $C_{b}$ と $C_{a} \cup C_{c}$ の領域は傾きが等しく, 切片が原点に対し て対称であることに注意すると，これらの領域はそれぞれ 次式で表現できる。

$$
\begin{aligned}
& C_{b}=\left\{\boldsymbol{y} \mid \boldsymbol{y}^{T} \boldsymbol{M y}<\left(V_{s w} T_{s}\right)^{2}\right\} \ldots \ldots \\
& C_{a} \cup C_{c}=\left\{\boldsymbol{y} \mid \boldsymbol{y}^{T} \boldsymbol{M} \boldsymbol{y} \geq\left(V_{s w} T_{s}\right)^{2}\right\}
\end{aligned}
$$

ただし，

$$
\boldsymbol{y}:=\left[\begin{array}{l}
y[k-1] \\
y[k-2]
\end{array}\right], \quad \boldsymbol{M}:=\left[\begin{array}{rr}
1 & -1 \\
-1 & 1
\end{array}\right] \ldots
$$


したがって，

$$
\begin{aligned}
& \boldsymbol{y}^{T} \boldsymbol{M} \boldsymbol{y}-\left(V_{s w} T_{s}\right)^{2} \\
& =y^{2}[k-1]-2 y[k-1] y[k-2] \\
& \quad+y^{2}[k-2]-\left(V_{s w} T_{s}\right)^{2} \ldots \ldots
\end{aligned}
$$

の正負によって $y[k]$ の軌跡が領域 $C_{b}$ と $C_{a} \cup C_{c}$ のどちら に存在するかを判別することができる。

以上の考察より, 2 次形式の非線形識別関数

$$
f(\boldsymbol{\varphi})=\boldsymbol{\varphi}^{T} \boldsymbol{M} \boldsymbol{\varphi}+b .
$$

を用いれば，回帰空間を mode 1 と mode 2 に分離できる ことがわかる。ただし， $\boldsymbol{\varphi}$ は回帰ベクトル， $\boldsymbol{M}=\left[m_{i j}\right]$ は 対称行列 $\left(m_{i j}=m_{j i}\right)$ である。なお，記述を簡単にするた め, $\varphi[k]$ を $\varphi$ と記述することにする。

さらに，(21) 式が多項式カーネルで表現できることを示 す。まず，

$$
\varphi=\left[\varphi_{1}, \varphi_{2}, \varphi_{3}, \varphi_{4}\right]^{T}
$$

とおき, 特徵空間への非線形写像を

$$
\begin{gathered}
\phi(\varphi)=\left[\varphi_{11}, \varphi_{22}, \varphi_{33}, \varphi_{44},\right. \\
\sqrt{2} \varphi_{12}, \sqrt{2} \varphi_{13}, \sqrt{2} \varphi_{14}, \\
\left.\sqrt{2} \varphi_{23}, \sqrt{2} \varphi_{24}, \sqrt{2} \varphi_{34}\right]^{T}
\end{gathered}
$$

で定義する。ただし，記述を簡単にするため $\varphi_{i j}:=\varphi_{i} \varphi_{j}$ と抄いた。そして $\boldsymbol{w} を$

$$
\begin{gathered}
\boldsymbol{w}=\left[m_{11}, m_{22}, m_{33}, m_{44},\right. \\
\sqrt{2} m_{12}, \sqrt{2} m_{13}, \sqrt{2} m_{14}, \\
\left.\sqrt{2} m_{23}, \sqrt{2} m_{24}, \sqrt{2} m_{34}\right]^{T}
\end{gathered}
$$

のように定義すると (21) 式は (6) 式で表現できる。ここで, $\langle\boldsymbol{\phi}(\boldsymbol{z}), \boldsymbol{\phi}(\boldsymbol{x})\rangle$ を計算しよう。

$$
\begin{aligned}
\langle\boldsymbol{\phi}(\boldsymbol{z}), \boldsymbol{\phi}(\boldsymbol{x})\rangle & \\
= & \left(z_{1} x_{1}\right)^{2}+\left(z_{2} x_{2}\right)^{2}+\left(z_{3} x_{3}\right)^{2}+\left(z_{4} x_{4}\right)^{2} \\
& +2 z_{1} z_{2} x_{1} x_{2}+2 z_{1} z_{3} x_{1} x_{3}+2 z_{1} z_{4} x_{1} x_{4} \\
& +2 z_{2} z_{3} x_{2} x_{3}+2 z_{2} z_{4} x_{2} x_{4}+2 z_{3} z_{4} x_{3} x_{4} \\
= & \langle\boldsymbol{z}, \boldsymbol{x}\rangle^{2} \ldots \ldots \ldots \ldots \ldots \ldots \ldots \ldots \ldots \ldots
\end{aligned}
$$

(22) 式は (7) 式に抢いて $d=2$ とした場合に相当するので, (21) 式の非線形識別関数は 2 次の多項式カーネルを用いる ことと等価であることがわかる。なお，上記は $\varphi \in \mathcal{R}^{4}$ た けでなく，任意の次元で成立する。

\section{4. シミュレーションによる検証}

$\langle 4 \cdot 1\rangle$ 入出力データと同定モデル 提案法の有效性 を検証するため, 速度の絶対值によって粘性摩擦が切り替 わるシステムに対しシミュレーションを行う。図 3 のパ ラメータを $m=2.5 \mathrm{~kg}, k=1 \mathrm{~N} / \mathrm{m}, V_{s w}=0.3 \mathrm{~m} / \mathrm{s}$,
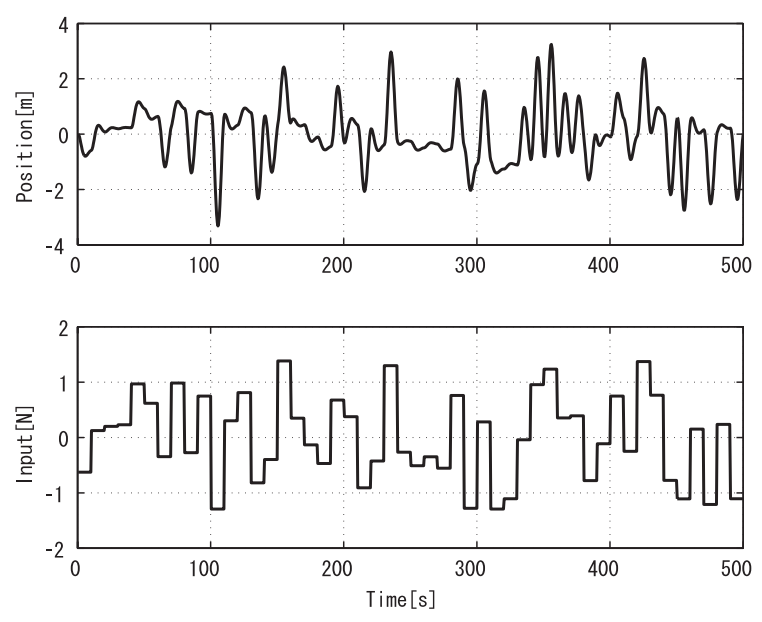

図 7 入出力デー夕 (上段 : 出力, 下段: 入力）

Fig. 7. Input-output data (upper: output, lower: input)
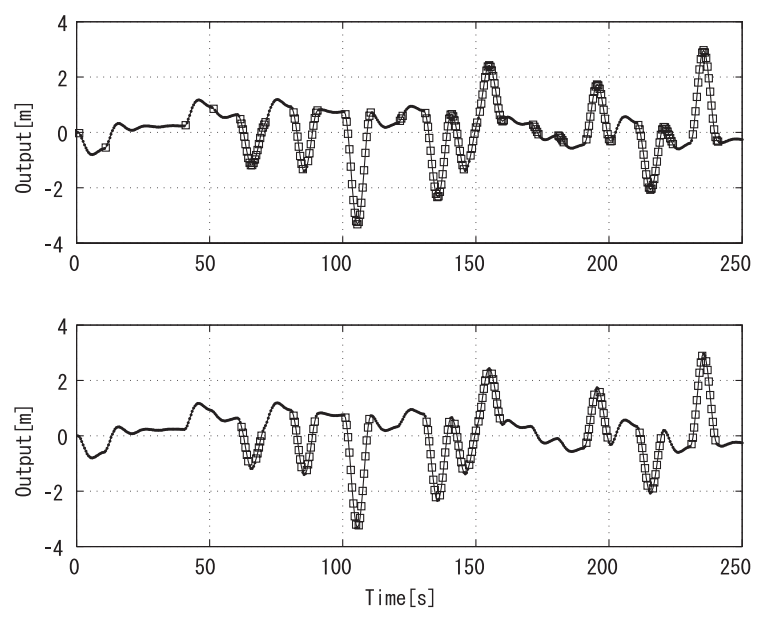

図 8 クラスタリング結果 (上段：クラスタリン グ結果, 下段：真のクラスタリング結果；点： mode 1 , 四角: mode 2)

Fig. 8. Clustering result (upper: clustered output, lower: true output; dots: mode 1, squares: mode 2)

$c_{1}=1.2 \mathrm{Ns} / \mathrm{m}, c_{2}=1.2 \times 10^{-3} \mathrm{Ns} / \mathrm{m}$ と与え, $T_{s}=0.5 \mathrm{~s}$ で離散化したのちに図 7 に示す入出力デー夕を収集した。 ただし，データ数は $N=1000$ であり，前半 500 個をモデ ル構築用, 後半 500 個をモデル検証用に用いた。同定モデ ルは次式のような 2 次の PWARX モデルとする。

$$
y[k]= \begin{cases}\boldsymbol{\theta}_{1}^{T} \boldsymbol{\varphi}[k]+w[k] & (\text { mode } 1) \\ \boldsymbol{\theta}_{2}^{T} \boldsymbol{\varphi}[k]+w[k] & (\text { mode } 2)\end{cases}
$$

なお， $w[k]$ は白色雑音であり， $\varphi[k]$ は (11) 式で定義され た回帰ベクトル, $\boldsymbol{\theta}_{i} \in \mathcal{R}^{4}, i=1,2$ は局所モデルのパラ メータベクトルである。

〈4・2〉 データクラスタリングと局所モデルの推定＼cjkstart回 帰ベクトルと出力からなるデータセット $(\varphi[k], y[k])$ を, $\langle 2 \cdot 1$ 節で述べた手順に従って mode 1 と mode 2 に分類 した。結果を図 8 の上段に示す。なお，今回は計算機上に 


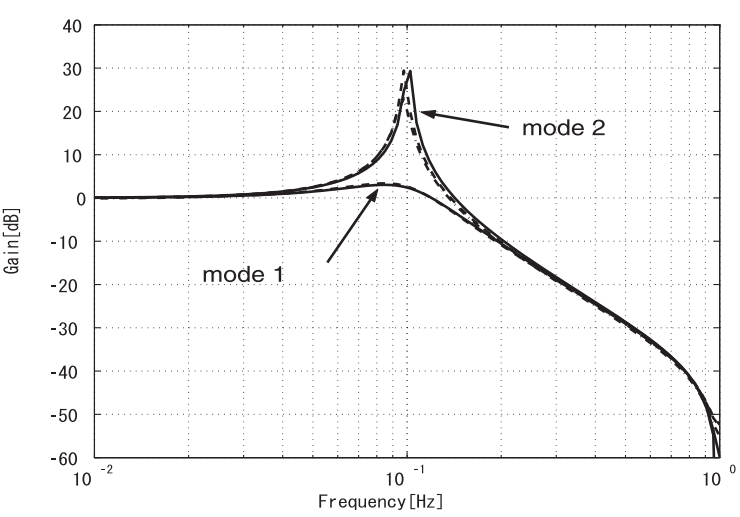

困 9 周波数応答 (実線： mode 1,2 の真の応答, 点線：mode 1 , 破線：mode 2 , 一点鎖線：単一 の ARX モデルによる同定結果)

Fig. 9. Frequency responses of identified submodels (solid line: true models of mode 1 and mode 2, dotted line: mode 1, dashed line: mode 2, dashdot line: single ARX model)

構築したモデルを用いて入出力データを生成しているため, 真のクラスタリング結果を知ることができる。これを，図 8 の下段に示した。上下の図を比較すると各マーカの位置が 対応しており，ほぼ正確にクラスタリングが行われている ことが確認できる。

クラスタリングされた結果をもとに mode 1 , mode 2 に 対するパラメータベクトル $\boldsymbol{\theta}_{i}$ を最小 2 乗法により推定し た。得られた ARX モデルの周波数応答を図 9 に示す。た だし，点線は mode 1, 破線は mode 2 を表す。これより， 得られた周波数応答は真の周波数応答とよく一致している ことがわかる。比較のため, 従来法として単一の ARX モ デルを仮定して得られたモデルの周波数応答を鎖線で示し た。mode 2 の特性しか得られていないことがわかる。

$\langle 4 \cdot 3\rangle$ SVM による回帰空間上の切り替え条件の推定 2 次の多項式カーネルを用いて回帰空間を mode 1 と mode 2 に分割する非線形識別関数 (21) 式を推定した。 その際，多少の誤差分類を許容するためにソフトマージ ン最適化を行った。な挹，多項式カーネルを用いた SVM のソルバーとしては，フリーで公開されている SVM and Kernel Methods Matlab Toolbox を用いた ${ }^{(6)}$ 。その結果 を図 10 に示す。ただし，回帰空間は 4 次元となるため, $\{-y[k-1],-y[k-2], u[k-1]\}$ を用いて 3 次元プロット した。また，2 方向から見た図を示している。これらの図 から, mode 1 と mode 2 を分離する境界面が推定できて いることが確認できる。

また，求めた局所モデルと切り替え条件を用いて時間領域 でのシミュレーションを行い，そのときの出力応答を図 11 に示した。図 7 の後半 500 個の出力データを実線, 通常の システム同定法による結果を破線，ハイブリッド同定によ る結果を鎖線で示す。ハイブリッド同定法の方が，応答がよ く一致している。適合率で比較すると，従来のシステム同定 法が $68.2 \%$ であるのに対し，ハイブリッド同定は $89.4 \%$ と
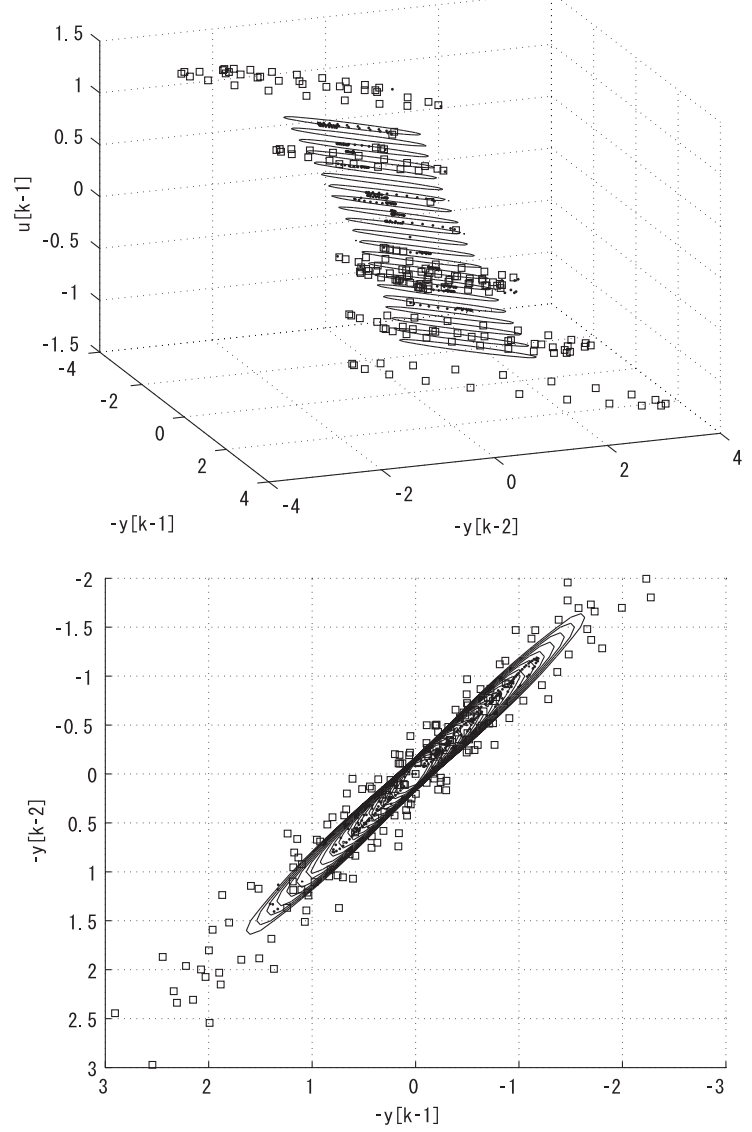

図 10 回帰空間 (点: mode 1, 四角: mode 2, 実 線：mode 1 と mode 2 の境界面)

Fig. 10. Regression space (dots: mode 1, squares: mode 2, solid line: estimated boundary between mode 1 and mode 2)

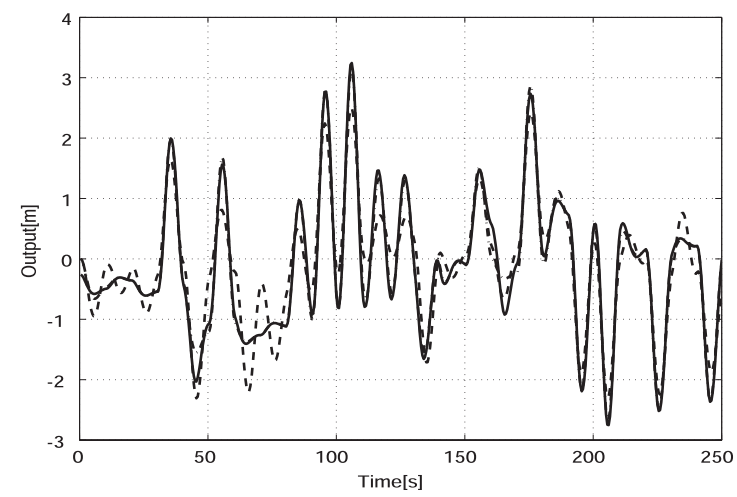

図 11 時間応答の比較 (実線, 真の応答, 破線： 単一の ARX を用いた場合, 鎖線：提案手法)

Fig. 11. Time responses of identified models (solid line: true model, dashed line: single ARX model, dashdot line: hybrid model)

なった。これらの結果から，速度の絶対值によってモデル が切り替わるシステムの場合, 多項式カーネルを用いた提 案法が有効であることがわかる。 


\section{5. おわりに}

本論文では，速度や変位の絶対值でバネ定数や粘性摩擦 係数が切り替わる 1 自由度振動系について考察した。そし て，このシステムを 2 つのモードをもつハイブリッドシス テムと仮定すると, 回帰空間上で回帰ベクトルを線形分割 できないことを示した。また，3つのモードに分割すると， 線形分割はできるものの，パラメータ空間と回帰空間が 1 対 1 に対応しないという問題が生じることを示した。そし て，これらの問題を解決するため, 多項式カーネルによる SVM を用いる手法を提案した。数值例により，各モードの パラメータが正しく同定できることを示した。さらに，同 定されたハイブリッドシステムの応答を，時間領域で評価 したところ，単一 ARX モデルを用いた従来のシステム同 定法に比べ，適合率が大きく向上することを示した。今後 は，本手法を実システムの同定問題に適用していきたい。

\section{謝 辞}

本研究の一部は科研費（18760314）及び（株）日立製作 所 中央研究所からの助成により行われた。ここに記して謝 意を表する。

(平成 19 年 4 月 9 日受付, 平成 19 年 12 月 3 日再受付)

\section{文献}

(1) G. Ferrari-Trecate, M. Muselli, D. Liberati, and M. Morari: "Identification of Piecewise Affine and Hybrid Systems", Proceedings of the American Control Conference, pp.3521-3526 (2001)

(2) N. Cristianini and J. Shawe-Taylor: "An Introduction to Support Vector Machines", Cambridge University Press (2000) (in Japanese) N. Cristianini, J.Shawe-Taylor 著, 大北 剛 訳： 「サポートベクターマシン入門」，共立出版 (2005)

(3) S. Adachi: "Advanced System Identification for Control Using MATLAB (Section 13)", Tokyo Denki Univ. Press (1996) (in Japanese)

足立修一：「MATLAB による制御のための上級システム同定 (第 13 章)」, 東京電機大学出版局 (2004)

(4) S. Noguchi, M. Hirata, and S. Adachi: "Hybrid Modeling of Hard Disk Drives Based on Input-Output Data", Proc. of SICE Annual Conference 2005, pp.1132-1135 (2005)

(5) S. Futami, A. Furutani, and S. Yoshida: Nanometer positioning and its micro dynamics, Nanotechnology, Vol.1, No.1, pp.31-37 (1990)

(6) S. Canu, Y. Grandvalet, V. Guigue, and A. Rakotomamonjy: SVM and Kernel Methods Matlab Toolbox, http://asi.insa-rouen.fr/ arakotom/toolbox/
平 田 光 男 （正員） 1969 年生 1 月 17 日生。1993 年 3 月千

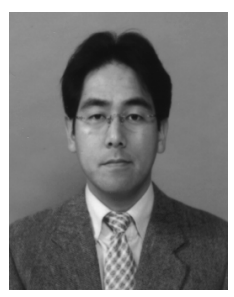
葉大学大学院大学工学研究科修了。1996 年 3 月 千葉大学大学院自然科学研究科修了。同年 4 月千 葉大学大学工学部助手, 2004 年 6 月宇都宮大学 工学部助教授, 2007 年 4 月宇都宮大学工学部准 教授, 現在に至る。博士 (工学)。2002 年 8 月〜 2003 年 8 月カリフォルニア大学バークレイ校機 械工学科客員研究員。主としてロバスト制御理論, サンプル值制御理論，及びそれらの応用に関する研究・教育に従事。 著書に MATLABによる制御系設計，ナノスケールサーボ制御（東 京電機大学出版局) など。計測自動制御学会, システム制御情報学会, 日本機械学会，日本鉄鋼協会，IEEE などの各会員。

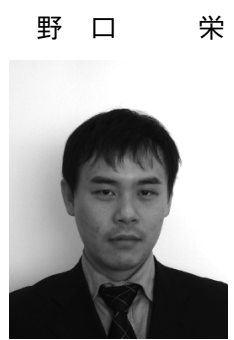

栄（非会員） 1982 年 5 月 28 日生。 2007 年 3 月 宇都宮大学大学院工学研究科電気電子工学専攻修 了, 同年 4 月いすが自動車 (株) 入社, 現在に至 る。在学中は, ハイブリッドシステムの同定に関 する研究に従事。

足 立 修 - (正員) 1957 年 10 月 19 日生。1981 年慶應義

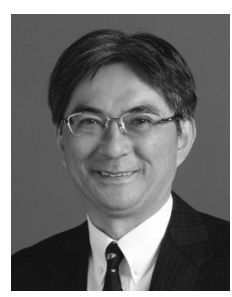
塾大学工学部電気工学科卒業。1986 年同大学院 博士課程修了, 同年 (株) 東芝総合研究所入社。 1990 年宇都宮大学工学部電気電子工学科助教授。 1993 1996 年 科学技術庁航空宇宙技術研究所客 員研究員。2002 年宇都宮大学工学部電気電子工 学科教授。2003 2004 年英国ケンブリッジ大学 客員研究員。2006 年慶應義塾大学理工学部物理 情報工学科教授, 現在に至る。工学博士。主としてシステム制御工学 全般に関する理論研究と産業応用研究に従事。著書に MATLABに よる制御のためのシステム同定（東京電機大学出版局）など。計測自 動制御学会, 日本鉄鋼協会, システム制御情報学会, 日本機械学会, IEEE などの各会員。 